\title{
MANAGEMENT IN ELECTRICITY SUPPLY
}

$\mathrm{M}$ R. C. T. MELLING'S inaugural address as president of the Institution of Electrical Engineers, delivered on October 11, might be said to constitute a study of management related particularly to the electricity supply industry.

Pointing out that electricity has become almost ubiquitous in its application, being nowadays basic to industrial, commercial, domestic and rural life, Mr. Melling observed that the electricity supply industry's future growth would influence powerfully Great Britain's development as a manufacturing nation. It was, he said, an industry characterized by very rapid technological development and a high rate of growth. These in themselves produced financial problems of great magnitude and, over and above, the industry had undergone several drastic changes of organization. The supply industry will have to solve technical, economic and financial problems of great complexity.

In fulfilling its fundamental purpose of supplying electricity to consumers, the industry operates as a business with public service responsibilities. Business management, combined with public service, formed the incentive in building up electricity supply in the various independent organizations, public and private, which, prior to nationalization, constituted in their aggregate the national system. Principles and practices so established duly influenced the terms of the Electricity Act of 1947 which, in creating a single nationalized system, exemplified in some ways the principle that in codifying what is to be done, legislation should incorporate the best of what is already being done.

In summarizing the general duties of a supply authority Mr. Melling distinguishes nine separate areas of activity. The first of these which, in some sense comprehends, by implication, all the others, may be quoted in full: "to ensure within the framework of a sound financial policy that, by forecast planning and construction, there is sufficient but not extravagant, generation transmission and distribution capacity to meet demands as they arise and that, consistent with reliability and good service, there is economy in capital and operating costs".

In other paragraphs are briefly stated the requirements of a sound tariff structure and a vigorous commercial policy together with the important duties of fostering good employer-employee relations and of good public relations. The pursuit of research, the improvement of efficiency, the development of a good consumer service and the achievement of co-ordination, constitute the subjects of the further paragraphs.

As a first example of a general management problem Mr. Melling took that of the organization of an area board following the nationalization of the industry in 1948. Nationalization, abolishing existing undertakings and establishing new bodies, might under one area board incorporate some forty separate undertakings. Any process of re-organization tends to produce, in employees who will be affected, a sense of uncertainty and possibly of apprehension, and such an operation on a national scale might well have been expected to be accompanied by some degree of disorganization. In fact the transition from the old system to the new was effected quite smoothly, a result to be attributed largely to the momentum of existing practices and to the competence and the good spirit of the people in the industry.

Decentralization of the consumer service was the keynote of the organization of the area boards. It was the aim that district managers should be truly responsible managers for their districts who, working within the framework of a sound practical policy, would have confidence and freedom in their day-to-day operations and in the exercise of their judgment in their relations with employees, consumers, local authorities and the public. Of paramount importance was the maintenance of communication and consultation to keep rank-and-file employees properly informed and to gain their active interest and co-operation in the efficient and economical working of the organization. There are, established by statute, organizations for the negotiation between management and employees representatives of wages, salaries and conditions of service and, similarly, for joint consultation on safety, health and welfare, education and training. These measures will, however, be ineffective unless they really 'permeate' the system. That is to say, the requirement is not met by formal compliance with an instruction to meet at specified intervals but only by top management directly and personally informing and consulting middle management which in turn will do the like with lower management. Thereafter, foremen and supervisors must inform and consult the employees under their direct control. Information must be transmitted promptly along the established chain of command, for the 'short circuiting' of authority at any level undermines confidence and engenders disaffection.

Numerous detailed changes were made in the organization of area boards in the years following nationalization. Unduly small districts were combined to form larger distribution units and experiments were made in the arrangements for repair workshops and stores. Operating practices were analysed and work studies undertaken.

By considering the effects of changes on individual employees and by avoiding undue haste, improvements were made more effectively and resulted in real rather than paper economies. Excluding the cost of bulk supplies of electricity the operating costs of area boards (pence per $\mathrm{kWh}$ sold) have been reduced in the ten years to March 1962 by about 16 per cent. This, taking into account the diminished value of money in the same period, represents a real saving of some 45 per cent.

The urge for further economies continues and there are new problems arising from developments in technology. and new operating techniques and, underlying everyone of these, is the basic problem of human relations. While it is essential that there should be a dynamic and enterprising spirit in relation to improvements, it remains true that large-scale changes in internal organization are just as disturbing to many people as general changes imposed by legislation. It is to be hoped that there can now be a period of stability and consolidation.

Mr. Melling chose in his second example of a general management problem to deal with certain specific issues in commercial development. The provision of the eorrect generation, transmission and distribution capacity to meet future demand depends on accurate forecasting. The trend from which such forecasts must be made depends on the antecedent period over which the trend is determined and herein lies the matter of judgment. Periods of depression or of industrial recovery are reflected in an oscillation of the rate of growth curve but, of course, each cycle varies from its predecessor. Based on a tenyear trend curve a compound interest factor of 7.6 per cent is obtained, but owing to the more rapid rate of increase in demand during the past few years a figure of 7.9 per cent is at present being utilized.

The industry's annual capital investment is approaching $£ 500$ million, which represents some 10 per cent of the nation's total capital investment. While it is clear that the present rate of increase of demand cannot continue indefinitely, it is unlikely that estimates of growth during the next few years are over optimistic. Great Britain still lags considerably behind the United States in the per 
capita consumption of electricity. It is, however, interesting to note that if in six years the present forecast should prove to be over-optimistic by, say, $500 \mathrm{MW}$ the additional capital changes would be noarly offset by savings in operating costs as a corresponding amount of the least efficient plant in operation could be taken out of service and scrapped.

Modern statistical techniques and computer studies are utilized on long- and medium-range forecasting. Distribution requirements having essentially a local and to some extent an individual character remain largely matters of judgment on the part of management.

Research is a primary factor in promoting the commercial development of the industry. For engineering research the supply industry has in the past relied largely on manufacturers and the co-operative work of the Electrical Research Association. It has, however, been realized that the industry requires to conduct a considerable research programme of its own and on this an amount of about $£ 6$ million is being spent per annum.

It is clear that insufficient national offort has boen directed to matters in which the characteristics of the consumer are of importance. Physiological, psychological and economic factors are involved. For example, the use of 'off peak' supplies for domestic and industrial purposes is increasing rapidly. Electric floor warming introduces a number of novel problems. Not least among the problems requiring investigation is that of the economies of such novel types of load. From the point of view of management, judgment and appraisal have to be applied to determining the sums to be allocated to research in its various aspects, and to the weight to be given to scientific and engineering opinion in the wider context of commercial and social implications. Management must, in fact, endervour to provide conditions in which engineers, physicists, mathematicians, economists and statisticians can co-operate fully and effectively in advancing the practice of electricity supply.

In the matter of tariffs, management has not only the overriding responsibility of ensuring an adequate total revenue but also a considerable power of influencing the development of demand in desirable directions. While there must be no undue preference for or discrimination against any consumer or class of consumer, there are opportunities for devising special tariffs which can be not only related to the special requirements but also can conduce by better distribution of demand to improvementis in the overall operation of the system.
Mr. Melling's third example was the most fundamental one-that of ensuring a supply of managers for one or two decades ahead. In the direct exercise of their professions, engineers, physicists, accountants or lawyers might give quite a good indication of thoir promise within a few years of graduation. The development of the potential manager and the demonstration of his qualities is a slower process. In Mr. Melling's opinion engineering provides, for management, as good a background as any other profession.

The supply industry, in developing its future managers, utilizes techniques common to most progressive industries. Potential managers attend courses in the industry's own residential training establishments, in universities and elsewhere. At the Electricity Council's training centre in Surrey are provided two types of course, one designed to promote general executive development through the medium of tackling unfamiliar problems by the syndicate method. The other studies individual subjects of importance to managers such as communication, organization and finance. The Generating Board and individual area boards organize similar training courses to meet their own needs. The facilities of the Administrative Staff College at Henley are also used.

Within the actual operating organization itself a system of regular appraisal is being used. This is designed to assess the potential of individuals and to formulate a scheme of training appropriate to individual needs. Following appraisal, selected members of staff may be sent on courses, given 'cross-postings' to new typos of work, or allocated to specific assignments. The aim is to provide exposure to some type of problem which has not been met before and which will exemplify human, as well as technical and economic, factors.

Many problems in any sphere of activity are necessarily those of the specialist, and management, in exercising judgment, is as often concerned to assess the qualities of the expert as the advice which he offers.

Academic qualifications, experience, and in some measure knowledge and intelligence are susceptible of direct assessment. The assessment of the qualities of the potential manager which relate to character and personality remains one of the most difficult of problems.

Mr. Melling completed his address by reviewing the role of the Institution of Electrical Engineers in fostering, through the Institution's educational requirements, the development of potential managers.

J. GREIG

\section{THE DRAGON HIGH-TEMPERATURE REACTOR PROJECT}

$\mathrm{T}$ HE third annual report of the Organization for European Co-operation and Development High Temperature Reactor Project (Dragon), covering the period from April 1, 1961 to March 31, 1962, has been issued by the European Nuclear Energy Agency*. The participants in the Project are the United Kingdom Atomic Energy Authority ; the Euratom Commission, consisting of the six countries, Belgium, France, Germany, Italy, Luxembourg and the Netherlands ; the Austrian Government ; the Danish Atomic Energy Commission ; the Norwegian Institut for Atomenergi ; $A B$ Atomenergi of Sweden; and the Swiss Government. The Project, which is based at Winfrith, Dorset, has as its principal aims the design, construction and operation of a $20-\mathrm{MW}$ high-temperature gas-cooled reactor, and a programme of research and development to explore the practical possibilities of this type of reactor and the technical problems resulting from

* Organization for Ficonomic Co-operation and Development: European Nuclear Energy Agency, O.F.C.D. Dragon High Temperature Reactor Project-Third Annual Report, 1961-6\%. Pp. 196. (Paris: Organization for Economic Co-operation and Development: European Nuclear Energy
Agency, 1962.) operation with temperatures close to $1,500^{\circ} \mathrm{C}$ in the core of the reactor. The Dragon reactor is not the only hightemperature reactor under construction. A similar reactor HGTR is being built for the Philadelphia Electric Company at Peach Bottom in the United States, and there has been continuous and close collaboration between the members of the United States Atomic Energy Commission and members of the Project concerning materials for the reactor cores, reactor physics and common design problems. The Dragon reactor is likely to be the first of the high-temperature reactors to be brought into operation. Fuel loading was expected to commence towards the end of 1962.

For 1961-62 expenditure on the Project is estimated at about $£ 4,000,000$ and for $1962-63$ about $£ 5,400,000$. The total cost of the original five-year programme ending in 1964 is now estimated at about $£ 15,000,000$, and a working party has been set up to examine the question of an extension of the five-year agreement. (It has recently been announced that the extension has been approved; Nature, 197,$129 ; 1963$. ) 